\title{
COMUNICAÇÃO
}

\section{INCIDÊNCIA DA MALÁRIA EM ALGUNS MUNICÍPIOS DAS REGIÕES NORTE E CENTRO-OESTE DO BRASIL, EM 1990.}

\author{
Superintendência de Campanhas de Saúde Pública
}

Relação dos Municipios com maior registro de malária ano:1990

\begin{tabular}{cllcc}
\hline $\begin{array}{c}\text { No de } \\
\text { ordem }\end{array}$ & Municipios & Estados & $\begin{array}{c}\text { Lâminas } \\
\text { Positivas }\end{array}$ & $\begin{array}{c}\text { \% de parti- } \\
\text { cipação (*) }\end{array}$ \\
\hline 01 & Ariquemes & Rondônia & 50.924 & 9,09 \\
02 & Porto Velho & Rondônia & 44.285 & 7,91 \\
03 & Peixoto de Azevedo & Mato Grosso & 36.327 & 6,49 \\
04 & Matupá & Mato Grosso & 29.507 & 5,27 \\
05 & Itaituba & Pará & 22.609 & 4,04 \\
06 & Jaru & Rondônia & 17.700 & 3,16 \\
07 & Terra Nova do Norte & Mato Grosso & 16.214 & 2,89 \\
08 & Boa Vista & Roraima & 15.002 & 2,68 \\
09 & Machadinho d'Oeste & Rondônia & 13.002 & 2,32 \\
10 & Ourilândia do Norte & Pará & 9.902 & 1,77 \\
11 & Guarantã do Norte & Mato Grosso & 9.527 & 1,70 \\
12 & Alta Floresta & Mato Grosso & 9.051 & 1,62 \\
13 & Costa Marques & Rondônia & 8.611 & 1,54 \\
14 & Aripuanãa & Mato Grosso & 7.212 & 1,29 \\
15 & Apiacás & Mato Grosso & 7.135 & 1,27 \\
16 & Santarém & Pará & 7.025 & 1,25 \\
17 & Redenção & Pará & 6.980 & 1,25 \\
18 & Ouro Preto & Rondônia & 6.453 & 1,15 \\
19 & Marabá & Pará & 6.250 & 1,12 \\
20 & Manaus & Amazonas & 5.534 & 0,99 \\
21 & Rio Branco & Acre & 5.453 & 0,97 \\
22 & Vila Nova do Mamoré & Rondônia & 5.096 & 0,91 \\
23 & Plácido de Castro & Acre & 5.064 & 0,90 \\
24 & Juína & Mató Grosso & 4.962 & 0,89 \\
25 & Curionópolis & Pará & 4.932 & 0,88 \\
26 & Macapá & Amapá & 4.769 & 0,85 \\
27 & Sta. Maria das Barreiras & Pará & 4.471 & 0.80 \\
28 & Imperatriz & Maranhão & 4.175 & 0,75 \\
29 & Mucajaí & Roraima & 3.956 & 0,71 \\
30 & Pontes e Lacerda & Mato Grosso & 3.569 & 0,64 \\
\hline Subtotal & & & 375.697 & 67,07 \\
\hline Total de exames positivos do pás em 1990 & & 560.143 & \\
\hline
\end{tabular}

Fonte: SUCAM / Divisão de Malária

(*): Em relação ao total de exames positivos do pais.

Dados: WK1 